\title{
SEMIÓTICA E AS AÇÕES COGNITIVAS DOS ALUNOS EM ATIVIDADES DE MODELAGEM MATEMÁTICA: UM OLHAR SOBRE OS MODOS DE INFERÊNCIA
}

\author{
Semiotics and students' cognitive actions \\ in Mathematical Modelling activities: a look at inference
}

Lourdes Maria Werle de Almeida ${ }^{1}$ Karina Alessandra Pessoa da Silva ${ }^{2}$

Resumo: Neste trabalho apresentamos algumas reflexões, à luz da semiótica peirceana, sobre a possibilidade de se introduzirem, na sala de aula, atividades que sinalizem potencial para se desenvolverem diferentes tipos de raciocínio e diferentes ações cognitivas nos estudantes. Iniciamos o trabalho com pressupostos teóricos da semiótica no que diz respeito aos modos de inferência abdução, dedução e indução e à Modelagem Matemática como alternativa pedagógica. Com o objetivo de investigar as relações entre as ações cognitivas evidenciadas em atividades de modelagem e os modos de inferência, analisamos uma atividade de modelagem desenvolvida por alunos de um curso de licenciatura em matemática. A partir dessa análise, concluímos que os modos de inferência ativados nessa atividade estão associados às ações cognitivas dos alunos durante as transições entre as diferentes etapas do desenvolvimento da atividade.

Palavras-chave: Educação matemática. Modelagem matemática. Semiótica. Cognição.

\begin{abstract}
In this paper we present some reflections, in the light of Peircean Semiotics, on the possibility of introducing into classroom, activities that signal the potential to develop different reasoning modes and different cognitive actions in students. We started working with the theoretical assumptions of semiotics in relation to the modes of inference abduction, deduction and induction and Mathematical Modeling as a pedagogical alternative. Aiming to investigate the relationships among cognitive actions highlighted in modeling activities and modes of inference, we analyzed a modeling activity developed by students of a course in Mathematics. From this analysis we conclude that the modes of inference activated in this activity are associated with cognitive actions of students during the transitions between the different stages of development activity
\end{abstract}

Keywords: Mathematics education. Mathematical modeling. Semiotics. Cognition.

\footnotetext{
${ }^{1}$ Departamento de Matemática, Centro de Ciências Exatas, Universidade Estadual de Londrina (UEL). Campus Perobal, Caixa postal 6001. Londrina, PR, Brasil. 86.051-990.lourdes.maria@sercomtel.com.br ${ }^{2}$ Pós-graduação em Ensino de Ciências e Educação Matemática, UEL. Londrina, PR, Brasil.
} 
Almeida, L. M. W.; Silva, K. A. P.

\section{Introdução}

As discussões que permeiam aspectos ligados à construção do conhecimento, especialmente no contexto escolar, nos diversos níveis de escolaridade, vêm sendo pautadas nas pesquisas em diferentes perspectivas.

Neste contexto, o ensino e a aprendizagem da Matemática, mediados por atividades investigativas que, de alguma forma, remetem à resolução de situações vinculadas a aspectos não matemáticos, têm sido assunto recorrente.

Neste trabalho apresentamos algumas reflexões sobre a possibilidade de se introduzirem, na sala de aula, atividades que sinalizem potencial para se desenvolverem diferentes tipos de raciocínio e diferentes ações cognitivas nos estudantes.

Para abarcar esta discussão, inicialmente, abordamos a semiótica de Peirce; e, fundamentados em Peirce $(1980,2005)$ e Santaella (2008), podemos considerar que esta constitui um propósito filosófico-analítico geral, cujo interesse são os fenômenos de produção de conhecimento. No entanto, considerando os propósitos e os alcances deste texto, tratamos apenas dos modos de inferência indução, abdução e dedução, cuja caracterização, na semiótica peirceana, apresentamos na terceira seção deste texto. Segundo Santaella (2007), os modos de inferência peirceana constituem uma função essencial da mente cognitiva, e a 'vida' do pensamento é uma questão de formação e/ou exercício de certos hábitos de inferência.

Neste encaminhamento, argumentamos que o estímulo dessas inferências nos alunos pode estar relacionado com a resolução de situações-problema, que, de modo geral, não são resolvidas por meio de procedimentos predefinidos, e cujas soluções não são previamente conhecidas.

Perante o desafio da introdução de atividades com esta conotação na sala de aula, tratamos da modelagem matemática. A caracterização da modelagem como prática investigativa defendida no texto nos permite argumentar que o desenvolvimento de atividades desse tipo viabiliza, aos alunos, um conjunto de ações cognitivas.

Neste contexto usamos o pressuposto de Kehle e Cunningham (2000) que estabelecem algumas relações entre as etapas de uma atividade de modelagem ${ }^{3}$ e os modos de inferência de Peirce (2005), caracterizando inferências abdutivas, indutivas e dedutivas durante o desenvolvimento de uma atividade de modelagem matemática.

Com o objetivo de investigarmos as relações entre as ações cognitivas abordadas nas etapas da atividade de modelagem matemática, e a semiótica no que diz respeito aos modos de inferência investigados por Kehle e Cunningham (2000), e Kehle e Lester Jr. (2003), analisamos uma atividade de modelagem desenvolvida por alunos do primeiro ano de um curso de licenciatura em matemática.

${ }^{3}$ Usamos o termo modelagem com o mesmo significado de modelagem matemática. 
Semiótica e as ações cognitivas dos alunos ...

\section{Sobre a semiótica de Peirce: aspectos relevantes para este trabalho}

A palavra semiótica advém do grego semeion, que significa signo, e a semiótica - do grego semeiotiké - é a ciência geral dos signos, os signos da linguagem. Segundo Correia (2007), a palavra grega semeiotiké foi introduzida na filosofia com esta designação pelo filósofo empirista inglês John Locke (1632-1704), em seu 'Essay on human understanding' no final do século XVII.

No início do século XX, o filósofo-lógico-matemático Charles Sanders Peirce (18391914) retoma este termo com seu sentido original a partir da Lógica concebida como uma filosofia científica da linguagem. Segundo Santaella (2008), a partir de 1857, Peirce preocupava-se com a organização de uma doutrina filosófico-analítica capaz de compreender as estruturas do conhecimento, e, assim, passou a fundamentar a semiótica (semiótica peirceana) como a ciência dos signos, que tem por objetivo o exame dos modos de produção de significado e de constituição de conhecimento.

Peirce (2005), concebendo a semiótica como a doutrina formal dos signos, definiu o signo como algo que, para uma pessoa, toma lugar de outra coisa (objeto), não em todos os aspectos desta coisa, mas de acordo com certa forma ou capacidade. A noção de signo para o autor, todavia, ultrapassa a natureza da linguagem como ato da fala ou da escrita, podendo ser, também, uma ação ou reação, que externaliza uma emoção ou um sentimento.

Ao definir signo, Peirce (2005) identifica três elementos sígnicos: o representámen, o objeto e o interpretante. $\mathrm{O}$ autor caracteriza esses elementos como sendo:

Um signo, ou representámen, é aquilo que, sob certo aspecto ou modo, representa algo para alguém. Dirige-se a alguém, isto é, cria na mente dessa pessoa, um signo equivalente, ou talvez um signo mais desenvolvido. Ao signo assim criado denomino interpretante do primeiro signo. O signo representa alguma coisa, seu objeto. Representa esse objeto não em todos os seus aspectos, mas com referência a um tipo de idéia que eu, por vezes, denominei fundamento do representámen. (PEIRCE, 2005, p. 46)

Charles Sanders Peirce, em sua teoria, estabelece uma relação entre signo e representação: "quando se deseja distinguir entre aquilo que se representa e o ato ou relação de representação, pode-se denominar o primeiro de 'representámen' e o último de 'representação"' (PEIRCE, 2005, p. 61). O autor considera que representar é "estar em lugar de, isto é, estar numa relação com outro que, para certos propósitos, é considerado por alguma mente como se fosse esse outro" (PEIRCE, 2005, p. 61).

Uma evidência nos diferentes trabalhos de Peirce é a caracterização do signo e suas relações com o pensamento e com a construção do conhecimento por meio de tríades ${ }^{4}$. Diver-

\footnotetext{
${ }^{4}$ Peirce (2005) sempre deu preferência à relação com três, estabelecendo relações entre palavras em forma de tricotomia, estabelecendo categorias entre fenômenos em número de três, e considerando a relação triádica que o signo pode estabelecer. Considerações aprofundadas sobre as divisões triádicas estão em Peirce (2005).
} 
Almeida, L. M. W.; Silva, K. A. P.

sas tricotomias peirceanas se tornaram conhecidas, no decorrer do tempo, como, por exemplo, primeiridade, secundidade e terceiridade, que originaram outras tantas subdivisões triádicas, que incluíam: signo, objeto e interpretante; ícone, índice e símbolo; qualidade, reação e representação e, também, dedução, indução e abdução.

Nosso interesse, neste texto, está no ramo da semiótica peirceana conhecida como lógica crítica, e que tem por estudo a tríade relativa aos modos de inferência ou argumento caracterizados por Peirce: dedução, indução e abdução.

Segundo Keske (2007), ao refletir sobre os processos de estruturação do pensamento, analisado em termos de linguagem, Peirce, em sua teorização, estabelece a inferência científica e considera estas três formas ou abordagens distintas e sistematizadas de se conhecer/interpretar um fenômeno.

A dedução é o modo de inferência mais simples. Ela se caracteriza por uma inferência que mostra de que forma, a partir de uma determinada regra geral, se estabelece um caso particular, obtendo-se um resultado considerado 'irrefutável' enquanto fenômeno lógico. Partindo de certas hipóteses (premissas), a dedução implica identificar o que nelas se encontra implicitamente suposto e, de modo geral, não requer muita criatividade, uma vez que não acrescenta nada que já não seja do conhecimento do intérprete. Em um processo dedutivo, as premissas (hipotéticas) são adaptadas às possibilidades materiais do fenômeno em observação.

O método indutivo, por sua vez, segundo Peirce (2005), ao contrário da dedução, parte de premissa menor e busca a generalização, permitindo verificar determinada teoria mediante a sua experimentação. Enquanto processo lógico-analítico, a indução é passível de ser experimentada e, por conseguinte, comprovada.

António Fidalgo (1998, p. 54) argumenta que, para Peirce, “a indução consiste em partir de uma teoria, dela deduzir predições de fenômenos a fim de ver quão de perto concordam com a teoria". Neste sentido, a indução é nitidamente um tipo de inferência mais sofisticado do que a dedução.

Diferenciando-se dos modos de inferência anteriores, a abdução caracteriza-se pela formação de novas hipóteses explicativas para um dado fenômeno. A abdução é uma espécie de intuição, de busca de uma conclusão pela interpretação racional de sinais, de indícios, de signos. Dos três tipos de raciocínio propostos, a abdução transforma-se, deste modo, naquele capaz de produzir/construir novos conhecimentos utilizando-se das premissas da dedução e das teorias supostas ou confirmadas pela indução. Umberto Eco considera que Peirce entende a abdução como "esse singular instinto de suposição, ou de inclinação para cogitar uma hipótese" (ECO, 1991, p. 19). Em uma abdução, temos de nos preparar para o estabelecimento de um resultado, no mínimo, curioso.

Em termos gerais, podemos considerar que a indução e a abdução são formas de pensamento relacionadas com a constituição de conhecimentos, enquanto, na dedução, nos ocupamos de verificar ou comprovar a veracidade de um conhecimento já constituído.

Eco (1991, p. 9), ao interpretar a teoria de Peirce, argumenta que cada modo de inferência manifesta-se como um silogismo, sendo ele mesmo um signo "cujo interpretante representa seu objeto como sendo um signo ulterior através de uma lei, ou seja, a lei segundo a qual a passagem de tais premissas a tal conclusão tende à verdade”. 
Semiótica e as ações cognitivas dos alunos ...

Segundo Santaella (2007), os modos de inferência ${ }^{5}$ peirceana constituem uma função essencial da mente cognitiva, e a 'vida' do pensamento é uma questão de formação e/ou exercício de certos hábitos de inferência.

Considerando a importância dessa formação e/ou exercício para a produção de conhecimento em ambientes acadêmicos, uma questão que merece atenção diz respeito ao desenvolvimento de atividades didáticas que oportunizem uma estruturação de pensamento com base nestes modos de inferência. Com esta perspectiva, tratamos da modelagem matemática na educação matemática.

\section{Sobre modelagem matemática na educação matemática}

Podemos dizer que, de modo geral, o termo modelagem matemática refere-se à busca de uma representação matemática para um objeto ou fenômeno não matemático. Considerando que esta busca pode ser realizada no âmbito de aulas de matemática, a modelagem matemática pode ser entendida como uma atividade na qual fazemos a abordagem, por meio da matemática, de uma situação-problema não essencialmente matemática (ALMEIDA; BRITO, 2005).

Segundo Almeida e Ferruzzi (2009), uma atividade de modelagem requer do aluno: a formulação de um problema e a definição de metas para sua resolução, a definição de hipóteses, a formulação de previsões e a apresentação de explicações e respostas para a situação em estudo, bem como a comunicação destas respostas e/ou explicações para outros.

Neste encaminhamento, ela se configura como uma atividade investigativa, conforme caracterização apresentada por Borges (2002 apud GOMES; BORGES; JUSTI, 2008, p. 187):

Atividades investigativas são atividades prático-experimentais propostas aos estudantes e que envolvem a resolução de problemas mal definidos e pouco estruturados. Problemas desse tipo não são resolvidos através da aplicação de procedimentos pré-definidos. Suas respostas não são conhecidas pelos estudantes, e às vezes, até pelos seus professores. Nelas os estudantes são desafiados a encontrar formas de coletar dados e informações que os levem a propor soluções razoáveis.

Considerando esta característica investigativa, um aspecto importante numa atividade de modelagem matemática é a necessidade de os próprios alunos, a partir de uma situaçãoproblema não matemática, fazerem a associação com conceitos e/ou procedimentos matemáticos capazes de conduzir a uma solução para o problema e possibilitar a sua análise.

Neste sentido, como atividade de investigação, o desenvolvimento de uma atividade de modelagem matemática requer do aluno um conjunto de ações cognitivas.

\footnotetext{
${ }^{5}$ Neste texto não adentramos nas demais discussões filosóficas sobre os modos de inferência indução e dedução. Apenas os tratamos conforme sua caracterização na semiótica peirceana.
} 
Almeida, L. M. W.; Silva, K. A. P.

\section{As ações cognitivas dos alunos em atividades de modelagem matemática}

De modo geral, uma atividade de modelagem matemática pode ser descrita em termos: de uma situação inicial (problemática), de uma situação final desejada (que representa uma solução para a situação inicial) e de um conjunto de procedimentos e conceitos necessários para passar da situação inicial para a situação final. Neste sentido, realidade (origem da situação inicial) e matemática (área em que os conceitos e os procedimentos estão fundamentados) passam a se integrar e, em diferentes momentos, conhecimentos matemáticos e conhecimentos extramatemáticos são acionados e/ou produzidos e integrados. A esta situação inicial problemática, a literatura costuma se referir como situação-problema; à situação final desejada é associado, de modo geral, um modelo matemático ${ }^{6}$.

À situação inicial a que nos referimos, podem estar associadas diversas representações, como: textos, tabelas, diferentes formas de gráficos etc. Já a situação final - modelo matemático - pode ser compreendida se considerarmos suas diferentes representações, como: a algébrica, a gráfica, a geométrica.

Os diferentes procedimentos a que nos referimos fazem com que as atividades de modelagem matemática viabilizem, aos alunos, a manipulação de diferentes representações dos objetos matemáticos.

Considerando a conceitualização da modelagem matemática que apresentamos e, apoiados em Gomes, Borges e Justi (2008), argumentamos que, em uma atividade de modelagem, identificam-se características fundamentais: a) envolve um conjunto de ações cognitivas do indivíduo; b) envolve a representação e manipulação de objetos matemáticos; c) é direcionada para objetivos e metas estabelecidos e/ou reconhecidos pelo indivíduo.

Ferri (2006) ao fazer uma análise de atividades de modelagem desenvolvidas por alunos, constrói um ciclo de modelagem numa perspectiva cognitiva a partir de procedimentos realizados pelos alunos nas atividades.

Neste artigo, na tentativa de se identificarem as ações cognitivas do indivíduo envolvido em uma atividade de modelagem matemática, é preciso considerar que este, ao se deparar com a situação real (situação inicial), identifica suas intenções e suas limitações para o desenvolvimento da atividade e a busca da situação final (uma resposta para o problema). Diante da atividade intencional, o indivíduo realiza ações cognitivas tanto implicitamente (por meio de procedimentos) como explicitamente (por meio de representações, de modo geral, simbólicas). A interação entre conhecimento matemático e conhecimento extramatemático, em certa medida, serve de pano de fundo para as ações cognitivas destinadas a apresentarem e explicarem a situação em estudo.

Quando o aluno se depara com uma situação-problema que pretende investigar, inicialmente precisa compreender o problema fazendo algumas aproximações ou idealizações, chegando ao que Ferri (2006) denomina de representação mental da situação. Consideramos

\footnotetext{
${ }^{6}$ Modelo matemático é um sistema conceitual, descritivo ou explicativo, expresso por meio de uma linguagem ou uma estrutura matemática, com a finalidade de descrever o comportamento de outro sistema e permitir a realização de previsões sobre este outro sistema (LESH; CARMONA; HJALMARSON, 2006).
} 
que a transição da situação-problema para a representação mental da situação implica diversas habilidades, como: entendimento da situação, apreensão de significado, interpretação de fatos e informações, agrupamento de ideias. O que se sabe sobre a situação, na representação mental da situação, corresponde já a um segundo estágio do conhecimento. Assim, entendemos que, nesta transição, a ação cognitiva que se pode identificar é a compreensão da situação.

A partir da representação mental da situação, os envolvidos com a atividade de modelagem precisam identificar o problema e definir metas para a sua resolução. A formulação de um problema para uma situação requer a estruturação e/ou simplificações deliberadas das informações acerca da situação. Assim, a ação cognitiva relevante que identificamos na identificação do problema é a estruturação da situação.

Compreender a situação-problema por meio da matemática implica procurar respostas para o problema suscitado por esta situação - respostas fundamentadas em um modelo matemático. A ação de matematização, também já caracterizada em Ferri (2006), que culmina na construção de um modelo matemático é fundamentada na definição e no julgamento de hipóteses que guiam a construção do modelo. Esta ação também vem revestida de uma transição de linguagens: a situação-problema se apresenta em linguagem natural e não parece diretamente associada a uma linguagem matemática; gera-se, assim, a necessidade da transformação de uma representação (linguagem natural) para outra (linguagem matemática). Esta linguagem matemática evidencia o problema matemático a ser resolvido; a elaboração de um modelo matemático é mediada por relações entre as características da situação e os conceitos, técnicas e procedimentos matemáticos adequados para representar matematicamente estas características, a organização de partes, a identificação de componentes.

A construção e/ou resolução de um modelo matemático com vistas a apresentar resultados matemáticos para o problema requer o domínio de técnicas e procedimentos matemáticos e uma coordenação adequada das diferentes representações associadas aos objetos matemáticos. Nesta ação cognitiva que denominamos sintese, tornam-se necessários: o uso de conceitos, técnicas, métodos e representações; a solução de problemas específicos usando-se conhecimentos prévios; a visão de padrões; o uso de ideias conhecidas para se criar novas ideias, e, em muitas situações, é adequado o uso de recursos tecnológicos. como software, por exemplo.

A análise de uma resposta obtida para o problema, inicialmente em termos de resultados matemáticos por meio do modelo matemático, constitui um processo avaliativo realizado pelos envolvidos na atividade. Nesta etapa, o aluno se depara com a necessidade de comparação e distinção de ideias, generalização de fatos, articulação de conhecimentos de diferentes áreas. A ação cognitiva dos alunos nesta transição é caracterizada como interpretação e validação, uma vez que diz respeito à análise da representação matemática associada ao problema, tanto em relação aos procedimentos matemáticos quanto a adequação da representação para a situação.

Finalmente, o desenvolvimento de uma atividade de modelagem matemática culmina com a comunicação de uma resposta do problema para outros. Esta comunicação implica, essencialmente, desenvolver uma argumentação que possa convencer, aos próprios modeladores e àqueles aos quais estes resultados são acessíveis, que a solução apresentada é razoável e é consistente, tanto do ponto de vista da representação matemática e dos artefatos matemáticos a ela associados quanto da adequação desta representação para a situação em estudo. Nesta ação, o aluno necessita: expor, para outros, o julgamento do valor de teorias e métodos; apresentar e justificar suas escolhas baseadas em argumentos racionalmente fundamentados, e 
Almeida, L. M. W.; Silva, K. A. P.

reconhecer que a situação requer alguma subjetividade. Assim, a comunicação e argumentação também constituem ações cognitivas dos alunos envolvidos em atividades de modelagem matemática.

A Figura 1 ilustra as diferentes etapas de uma atividade de modelagem matemática e as ações cognitivas dos alunos associadas às transições entre as diferentes etapas relativas ao desenvolvimento da atividade.

Figura 1. Etapas da modelagem matemática e as ações cognitivas dos alunos

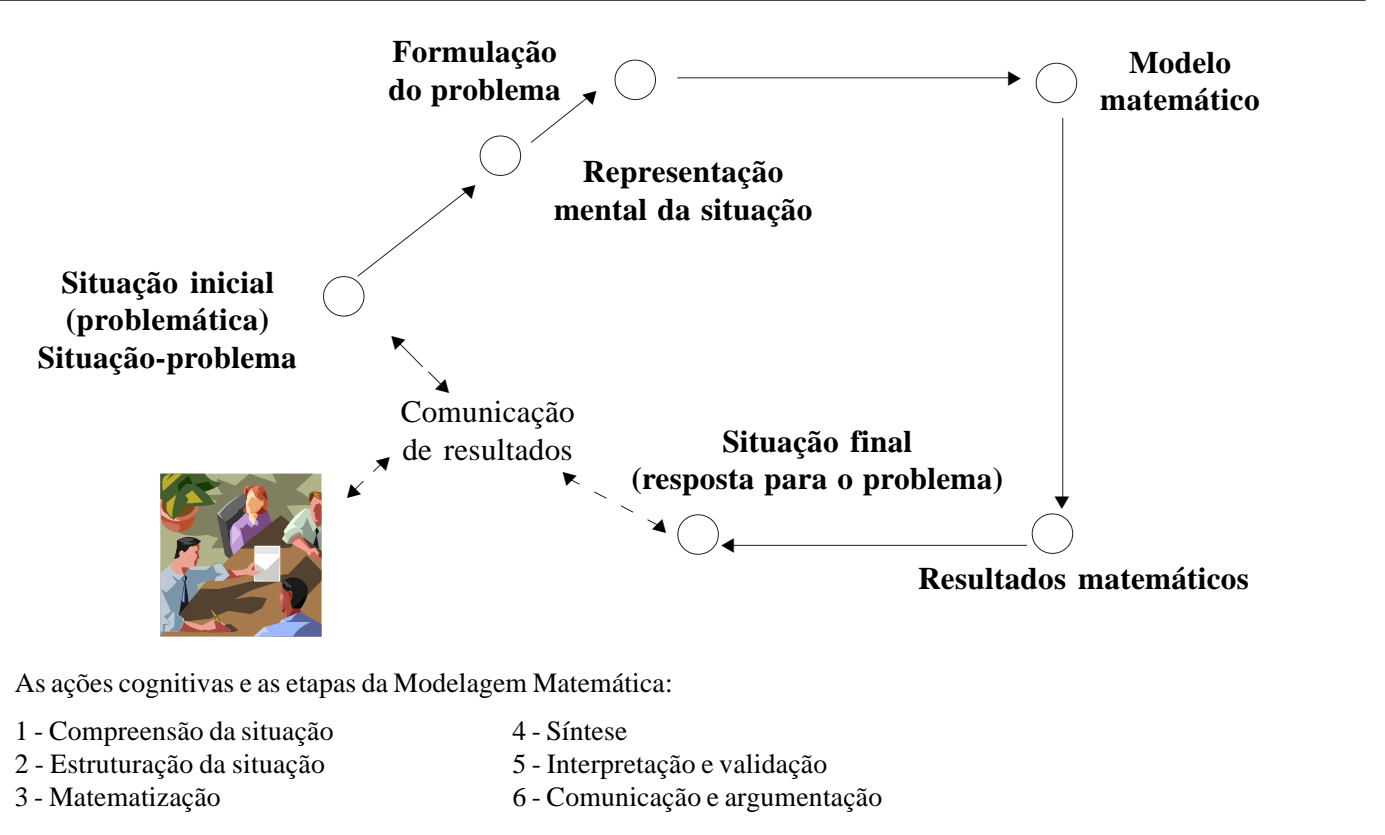

Fonte: Elaborada pelos autores

\section{Os modos de inferência de Peirce e as atividades de modelagem matemática}

A caracterização da modelagem matemática como atividade investigativa remete à argumentação de Klahr e Dunbar (1988) de que, em atividades dessa natureza, podem se identificar dois aspectos distintos, porém complementares: a formulação de hipóteses e a experimentação. Klayman e Ha (1987) defendem que as hipóteses, uma vez definidas, devem ser avaliadas segundo sua plausibilidade. Este julgamento está fundamentado no conhecimento e na familiaridade com o domínio conceitual e em diferentes estratégias experimentais. Neste sentido, na seção anterior, caracterizamos ações cognitivas dos alunos relativamente a estes dois aspectos identificados numa atividade de modelagem.

Neste momento, inferimos que a formulação e a análise de hipóteses, aliadas às estratégias experimentais que conduzem à proposição de conclusões para a situação-problema em estudo, remetem aos modos de inferência definidos por Peirce (2005). 
Semiótica e as ações cognitivas dos alunos ...

Ao abordarem o trabalho com os signos em atividades de modelagem matemática, Kehle e Lester Jr. (2003) consideram que uma atividade de modelagem está associada a uma instância de semiose - a ação dos signos -, argumentando que a semiose constitui uma contextualização seletiva no sentido de que signos geram signos. Isto é, signos associados a uma situação-problema geram signos associados a aspectos matemáticos associados a esta situação. Para tratar dessa ação dos signos, os autores associam a transição do contexto não matemático para o contexto matemático, bem como a definição de hipóteses e as estratégias experimentais relativas ao conjunto de procedimentos dos alunos para a obtenção e análise do modelo matemático, com os modos de inferência abdução, indução e dedução (Figura 2).

Figura 2. Modos de inferência acionados no desenvolvimento de uma atividade

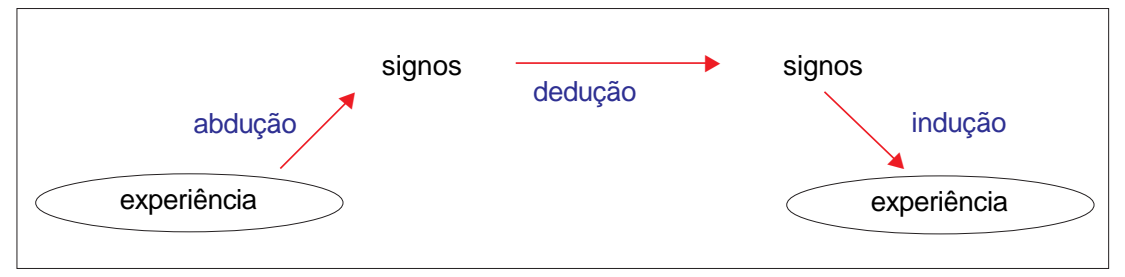

Fonte: Kehle e Lester Jr. (2003, p. 106)

Segundo esses autores, a abdução medeia a existência de uma situação-problema e a obtenção de um resultado. Eco (1991, p. 19) caracteriza a abdução como "singular instinto de suposição ou de inclinação para cogitar hipóteses”. Com base nessa caracterização, Kehle e Lester Jr. (2003) associam este modo de inferência: à apresentação de hipóteses ou palpites, à formulação de pistas, à apresentação de diagnósticos vinculados com a busca de signos para representar a situação, à realização de analogias e à explicação para o uso de determinada hipótese, variável ou procedimento.

Levando em consideração que a indução é caracterizada por Peirce (2005) como inferência que, partindo de caso particular, busca a generalização, e, fundamentados em Kehle e Lester Jr. (2003), associamos este modo de inferência com: a identificação das características do problema, a análise da plausibilidade das hipóteses e os procedimentos experimentais que viabilizam a construção do modelo matemático.

O modo de inferência dedução, por sua vez, é percebido por Kehle e Lester Jr. (2003), na atividade de modelagem, no momento da validação do modelo, que, como regra geral, deve se adequar à solução particular da situação em estudo.

No Quadro 1 constam as inferências associadas por Kehle e Cunningham (2000) aos modos de inferência identificados na teoria de Peirce, e suas respectivas caracterizações em uma atividade de modelagem matemática.

Cada um dos seis modos de inferência de abdução - palpite, sintoma, analogia, pista, diagnóstico e explicação - refere-se à potencialidade ou possibilidade de estudo de determinado fenômeno ou situação nova; cada um dos três modos de inferência de indução - identificação, verificação de hipóteses e construção do modelo - refere-se ao processo de matematização e adequação de hipóteses da situação; o modo de inferência dedução - validação - enfoca análises, deliberações de regras e regularidades necessárias para retornar à situação original. 
Almeida, L. M. W.; Silva, K. A. P.

Quadro 1. Modos de inferência de Peirce e modelagem matemática

\begin{tabular}{|c|c|c|}
\hline $\begin{array}{l}\text { Modo de } \\
\text { inferência }\end{array}$ & Inferência & Caracterização na atividade de Modelagem Matemática \\
\hline \multirow{6}{*}{ Abdução } & Palpite & $\begin{array}{l}\text { Realização de aproximações ou idealizações sobre as informações } \\
\text { iniciais para orientar a identificação do problema. }\end{array}$ \\
\hline & Sintoma & $\begin{array}{l}\text { A partir de uma análise, informações que, embora pareçam pouco } \\
\text { importantes, passam a ser consideradas necessárias para o } \\
\text { desenvolvimento da situação. Manifesta-se na transição entre a } \\
\text { situação-problema e a identificação do problema. }\end{array}$ \\
\hline & Analogia & $\begin{array}{l}\text { Os alunos manipulam comparações para criarem ou descobrirem uma } \\
\text { possível regra ou a identificação de possíveis padrões. }\end{array}$ \\
\hline & Pista & $\begin{array}{l}\text { A percepção de algumas evidências que sinalizam regras ou } \\
\text { procedimentos para a investigação do problema. }\end{array}$ \\
\hline & Diagnóstico & $\begin{array}{l}\text { Levantamento de hipóteses plausíveis fundamentadas nas informações } \\
\text { e no conhecimento dos alunos sobre o fenômeno em estudo. Evidencia } \\
\text { o entendimento da informação, a construção de significado. }\end{array}$ \\
\hline & Explicação & $\begin{array}{l}\text { Está relacionada com: o uso das hipóteses para fundamentar a } \\
\text { construção do modelo, o uso de métodos e técnicas para a construção } \\
\text { do modelo, bem como a interpretação dos resultados obtidos. Em } \\
\text { termos de explicação de resultados, diferentes representações podem } \\
\text { ser apresentadas pelos alunos. Revela a tradução de conhecimento } \\
\text { para novo contexto, interpretação de dados, comparação. }\end{array}$ \\
\hline \multirow{3}{*}{ Indução } & Identificação & $\begin{array}{l}\text { É um tipo de modo de inferência de indução. Refere-se à verificação de } \\
\text { uma possível regra usada ou definida, buscando a sua generalização } \\
\text { para o problema. }\end{array}$ \\
\hline & $\begin{array}{l}\text { Verificação de } \\
\text { hipóteses }\end{array}$ & $\begin{array}{l}\text { Está relacionada com: a demonstração da necessidade das hipóteses; } \\
\text { a análise das relações entre características do problema que } \\
\text { conduzem às hipóteses e os procedimentos matemáticos usados na } \\
\text { construção do modelo; a análise da relação entre a situação-problema } \\
\text { inicial e os resultados gerados com o uso da hipótese. }\end{array}$ \\
\hline & $\begin{array}{l}\text { Construção do } \\
\text { modelo }\end{array}$ & $\begin{array}{l}\text { As hipóteses, as regras, os conceitos usados geram uma estrutura } \\
\text { matemática que se refere à situação real e que pode ser validada. Esta } \\
\text { estrutura pode prever e testar variações do problema, por meio da } \\
\text { alteração de parâmetros. }\end{array}$ \\
\hline Dedução & $\begin{array}{l}\text { Procedimentos } \\
\text { avaliativos }\end{array}$ & $\begin{array}{l}\text { Inferência em que os sujeitos acabam por identificar, do modelo, o que } \\
\text { está nele implicitamente suposto para a situação. A verificação de que } \\
\text { determinada resposta não é adequada pode orientar a definição de } \\
\text { novas hipóteses ou de novos métodos ou técnicas para a obtenção de } \\
\text { respostas. }\end{array}$ \\
\hline
\end{tabular}

Fonte: Elaborado pelos autores a partir do texto de Kehle e Cunningham (2000)

\section{Os modos de inferência de Peirce e as ações cognitivas dos estudantes em atividade de modelagem matemática: a análise de uma atividade}

No percurso da situação-problema para o modelo matemático e sua validação em relação à situação inicial, durante uma atividade de modelagem matemática, os modos de inferência dos signos classificados por Kehle e Cunningham (2000) podem ser associados às ações cognitivas dos alunos. 
Esta associação está vinculada com o caráter pessoal da modelagem (o conhecimento e as ações de cada indivíduo influenciam o grau de dificuldade ou facilidade para alcançar a situação final desejada) e com características de cada atividade, uma vez que suas especificidades podem contribuir para que mais ou menos ações cognitivas sejam desencadeadas e que diferentes modos de inferência sejam evidenciados.

Subsidiamos nossas argumentações sobre estas associações na análise de uma atividade de modelagem matemática desenvolvida por um grupo de alunas do $1^{\circ}$ ano de um curso de licenciatura em matemática durante um curso extracurricular vinculado a projeto de pesquisa de um dos autores deste texto. A situação-problema foi espontaneamente escolhida pelas alunas, embora o desenvolvimento desse tipo de atividade fosse uma exigência do curso. As informações sobre o problema, as resoluções efetuadas e as transcrições de entrevista que apresentamos constam do relatório das alunas apresentado em Vertuan (2007) ${ }^{7}$ e em Silva (2008).

Nessa atividade, a situação-problema inicial das alunas está associada a uma figura de título "Justiça e qualidade de vida", da revista Veja de 30 de junho de 2004 (p. 39). A figura faz parte de uma reportagem intitulada "No coração do mercado" da mesma revista (p. 36), e mostra uma relação entre Índice de Desenvolvimento Humano (IDH) ${ }^{8}$ e a demora para análise de processos pela justiça dos países.

A partir da leitura deste texto, considerando as informações qualitativas e quantitativas apresentadas, as alunas visualizaram uma situação-problema e que é passível de investigação. A existência de relação entre o número de dias para resolver uma disputa comercial na justiça e a qualidade de vida de um país sinalizada no texto passou a ser a representação mental da situação dessas alunas. As informações do texto viabilizaram a definição dessa representação mental a partir: do entendimento da situação, da apreensão de significado, da interpretação das informações do texto e do agrupamento de ideias. Neste sentido, a ação cognitiva compreensão da situação pode ser percebida.

Em relação ao modo de inferência, conjecturamos que a abdução Palpite, em certa medida, orienta as ações das alunas nesta transição da situação-problema para a representação mental da situação, uma vez que as informações do texto encorajam as alunas a buscarem métodos para estabelecerem uma relação entre qualidade de vida e o número de dias para resolver uma disputa comercial na justiça.

Uma das informações da reportagem é o gráfico que apresenta informações fundamentais em relação à situação a ser investigada. É justamente por meio dos dados deste gráfico (Gráfico 1) que o grupo identifica o problema que pretende investigar. Neste caso, a inferência Sintoma faz com que o grupo perceba que os dados do gráfico são uma informação relevante da reportagem: os dados quantitativos necessários para se prosseguir a uma análise da situação estão nesta figura.

\footnotetext{
${ }^{7}$ Também ministrante do minicurso no qual a atividade foi desenvolvida.

${ }^{8}$ Essa medida indica o que, popularmente, denomina-se qualidade de vida. Os valores do IDH variam de zero (nenhum desenvolvimento humano) a um (desenvolvimento humano total). Países com IDH até 0,499 são considerados de desenvolvimento humano baixo; com índices entre 0,500 e 0,799 são considerados de desenvolvimento humano médio; e com índices maiores que 0,800 são considerados de desenvolvimento humano alto.
} 
Almeida, L. M. W.; Silva, K. A. P.

Gráfico 1. Os dados da revista

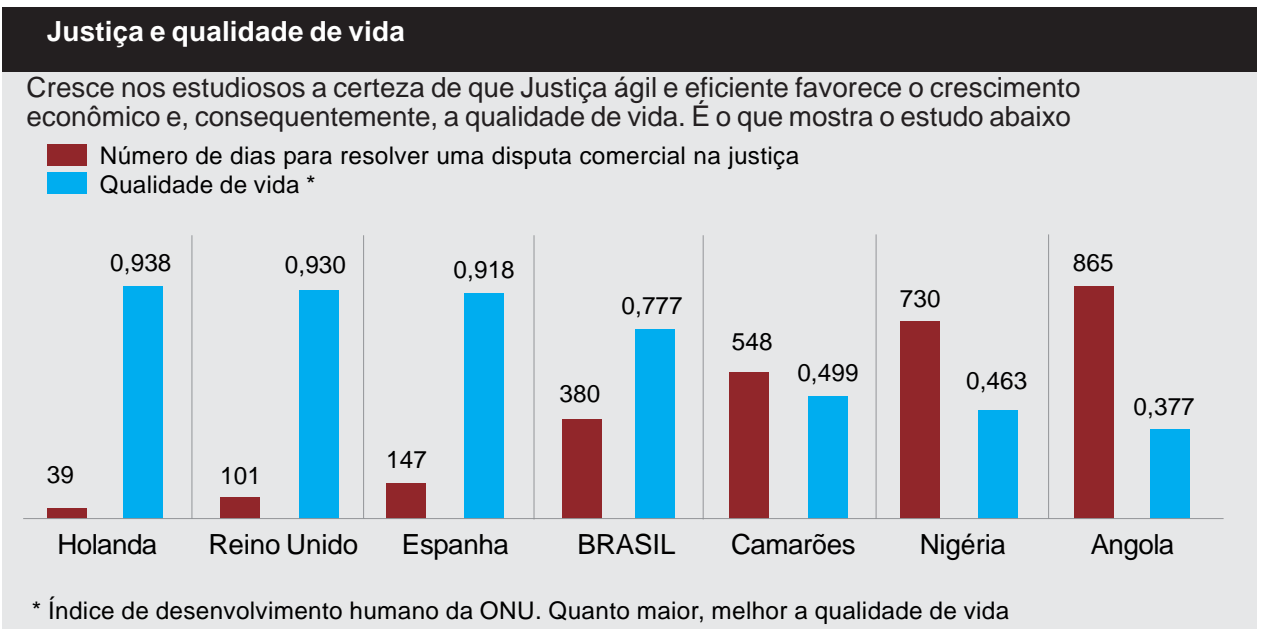

Fonte: Veja, São Paulo, 30 jun. 2004, p. 39. Disponível em: http://veja.abril.com.br/acervodigital/home.aspx

Kehle e Cunningham (2000) afirmam que os signos, como os apresentados no Gráfico 1, envolvem modos de inferência de abdução, pois partem da experiência, da realidade. Isto pode ser associado com o fato de que, quando as alunas observaram esta figura, elas observaram um signo, que representa algo em lugar de outra coisa e, a partir desse signo, se propuseram a estudar um problema. Segundo Santaella (2007, p. 15), “os signos só podem se reportar a algo, porque, de alguma maneira, esse algo que eles denotam está representado dentro do próprio signo", e, nessa atividade, as alunas evidenciaram este "algo" representado.

Passar da representação mental para a definição de um problema a ser investigado requer: a definição de metas para o estudo, a estruturação deliberada de uma pergunta, e o uso consciente das informações da reportagem - o que sinaliza que a ação cognitiva estruturação da ação é o que rege os procedimentos das alunas nesta etapa. É esta ação cognitiva que orienta a definição do problema: como o número de dias para resolver uma disputa comercial na justiça pode influenciar na qualidade de vida de um país, e qual a redução necessária no número de dias, no caso do Brasil, para que o país atinja um índice de desenvolvimento humano (IDH) mais elevado?

A habilidade das alunas em definir, a partir das informações do texto, um problema que vislumbram resolver por meio da definição de hipóteses e da execução de procedimentos, sinaliza que realizam a inferência de abdução Pista caracterizada no Quadro 1.

Considerando as informações do Gráfico 1, o problema que o grupo oficialmente apresenta é o exposto no Quadro 2.

Quadro 2. O problema definido pelas alunas

Definição do problema:

- Encontrar um modelo matemático que descreva como o número de dias para resolver uma disputa comercial na justiça pode influenciar na qualidade de vida de um país. Usando este modelo, verificar qual a redução necessária no número de dias para que o Brasil atinja um IDH alto, ou seja, IDH=0,8. 
Semiótica e as ações cognitivas dos alunos ...

Considerando o interesse do grupo em fazer uma análise para o caso particular do Brasil, do ponto de vista matemático, é necessário que o modelo encontrado viabilize determinar em que intervalo uma pequena variação na quantidade de dias para resolver uma disputa comercial na justiça pode produzir uma melhora significativa na qualidade de vida.

Para a resolução deste problema, as alunas precisam se envolver com os aspectos identificados na atividade de modelagem: a formulação de hipóteses e a experimentação.

Em primeira instância, buscando um modelo matemático, estes aspectos remetem à ação cognitiva matematização. A primeira habilidade dos alunos neste momento reside na capacidade de realizar a transição de linguagem, buscando uma linguagem matemática para o problema. Neste sentido, a apresentação de outras representações para os dados quantitativos do Gráfico 1 sinaliza a realização desta transição. A tabela da Figura 3 é outra representação associada às informações do Gráfico 1.

Figura 3. Diferentes representações para as informações

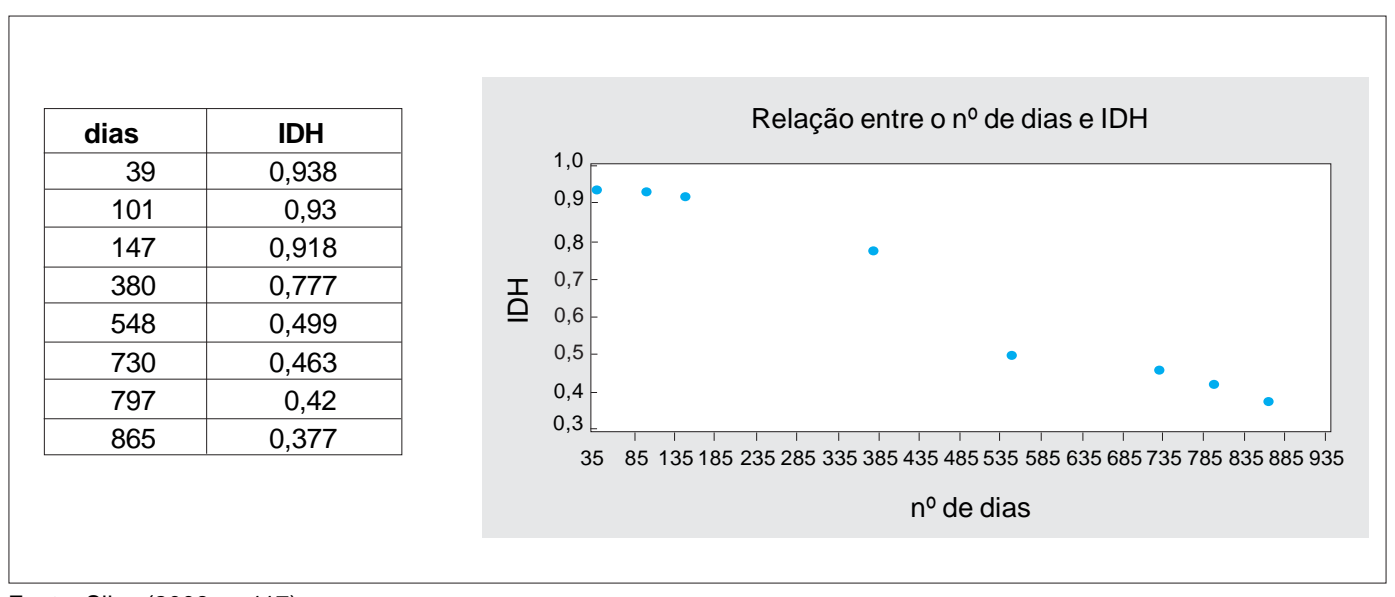

Fonte: Silva (2008, p. 117)

Evoluindo na matematização da situação, a partir dos dados do Gráfico 1 e da tabela da Figura 3, as alunas definem variáveis (apresentadas no Quadro 3) para orientar a obtenção do modelo matemático.

Quadro 3. As variáveis do problema

Seleção das variáveis
j: número de dias para resolver uma disputa comercial na justiça
Q(j): qualidade de vida em função do número de dias

Fonte: Silva (2008, p. 114) 
Almeida, L. M. W.; Silva, K. A. P.

Esta definição de variáveis remete as alunas à representação dos dados no plano cartesiano, conforme mostra o gráfico da Figura 4. Uma análise destas representações usando conhecimentos matemáticos e extramatemáticos fundamenta a definição de hipóteses, conforme mostra o Quadro 4. Nesta etapa do desenvolvimento da atividade de modelagem matemática, as alunas fizeram generalizações, perceberam algumas regularidades nos dados obtidos e raciocinaram logicamente. Certamente, a hipótese 2 é uma 'criação' matemática das alunas para resolver o problema, uma vez que, em termos da situação real, não existe país em que processos judiciais sejam resolvidos em 'zero' dias. Todavia se isso acontecesse, a conjectura das alunas é de que o índice que mede a qualidade de vida teria valor máximo (um).

O levantamento das hipóteses - embora ainda seja a definição de como características do problema podem ser tratadas em linguagem matemática (matematização) - requer das alunas o uso de conhecimentos prévios, a visão de padrões e a análise das diferentes representações associadas às informações que subsidiam o problema. Assim, em termos de ações cognitivas, as alunas realizam o que caracterizamos, em seção anterior, como síntese.

Quadro 4. As hipóteses para o desenvolvimento da atividade de Modelagem Matemática

\begin{tabular}{|l|}
\hline Levantamento de hipóteses \\
\hline Hipótese 1: A qualidade de vida em função do número de dias para resolver uma questão \\
comercial na justiça pode ser descrita por uma função definida por partes, sendo uma \\
quadrática no primeiro intervalo e uma exponencial no segundo intervalo. \\
Hipótese 2: $Q(0)=1$
\end{tabular}

Fonte: Silva (2008, p. 116)

No que diz respeito à definição das hipóteses, parecem se configurar duas situações. Inicialmente, para a definição da hipótese 1 , o uso de diferentes representações para as informações (Gráfico 1 e Figura 3) sinaliza a inferência Analogia; todavia a hipótese das alunas de usar uma função definida por partes, provavelmente decorrente da representação dos dados em plano cartesiano, corresponde ao modo de inferência de abdução Sintoma. Esse procedimento das alunas está em sintonia com a argumentação de Santaella (2008, p. 51) de que a analogia "dá à experiência seu caráter factual”. No que diz respeito à definição da hipótese 2 , as alunas teceram algumas considerações sobre a questão de que, se uma disputa comercial levasse zero dias para ser resolvida, o país apresentaria IDH $=1$, que é o índice máximo considerado; esta conjectura das alunas sinaliza a inferência de abdução Sintoma.

A partir das hipóteses estabelecidas, o grupo faz uso de um conjunto de técnicas e conceitos matemáticos, além do uso de software (Curve Expert) para construir o modelo que descreve a situação, conforme mostra o Quadro 5.

Neste momento, conforme relatado em Silva (2008), as alunas sentiram necessidade de fazerem alguns incrementos, criando novos pontos para acrescentar aos da tabela apresentada na Figura 3 para viabilizar a construção das funções quadrática e exponencial, respectivamente, conforme conjecturam na hipótese 1. Assim, aos dados da tabela da Figura 3, as alunas acrescentaram os pontos $(19,5 ; 0,969)$ (construído como ponto médio entre $(0 ; 1)$ e o primeiro ponto da tabela) e $(797,5 ; 0,420)$ (ponto médio dos pontos $(730 ; 0,463)$ e $(865 ; 0,377)$ constantes 
Semiótica e as ações cognitivas dos alunos ...

da tabela da Figura 3). Estes procedimentos das alunas refletem a ação cognitiva síntese e o modo de inferência de abdução Diagnóstico. Esta ação das alunas, de 'criar' novos pontos e escolher de forma adequada os pontos para construir o modelo matemático, também sinaliza uma inferência indutiva do tipo Identificação. A indução, nesses termos, está sinalizada na ação das alunas de - ao levarem em consideração uma situação particular manifestada nas representações - deliberarem que este é o 'comportamento' de uma função definida por partes, sendo, quadrática e exponencial, respectivamente, nos intervalos percebidos nas informações.

Quadro 5. O modelo matemático para a atividade

As alunas ajustaram uma função quadrática aos dados no intervalo $(0,380]$, obtendo:
$Q(j)=-0,000000617 . j^{2}-0,000297 . j+0,979$, se $\quad 0<j \leq 380$
Para o intervalo $(380, \infty)$ as alunas ajustaram uma função do tipo $Q(j)=a . b^{i}$, obtendo:
$Q(j)=1,136.0,999{ }^{j}$, se $\quad j>380$
$\begin{aligned} & \text { Assim, a função que descreve a qualidade de vida em função do número de dias para resolver um problema } \\ & \text { na justiça é dada por: }\end{aligned}$
$Q(j)=\left\{\begin{array}{c}-0,000000617 . j^{2}-0,000297 . j+0,979, \text { se } \\ 1,136.0,999{ }^{j}, \text { se } \quad j>380\end{array}\right.$

Fonte: Silva (2008, p. 123)

Uma compreensão mais completa do comportamento do IDH em função do número de dias pode ser visualizada usando-se uma representação gráfica, conforme mostra a Figura 4. Neste caso, um conhecimento refinado sobre as características do modelo obtido, bem como o uso adequado do software são fundamentais para que todas as características do modelo se tornem conhecidas. A descontinuidade da função para $j=380$, apontada no gráfico do modelo na Figura 4, é uma situação que requer atenção para não passar despercebida. As alunas perceberam assim que para $j=380$ o ponto $(j, Q(j))$, é um ponto crítico da função definida por partes (o modelo matemático) que obtiveram. Uma análise mais completa determina que este é o único ponto em que o modelo obtido é uma função não contínua. Esta análise corresponde, na classificação de Kehle e Cunningham (2000), a uma inferência dedutiva Procedimento Avaliativo.

O modelo obtido, entretanto, ainda não representa a solução completa do que o grupo se propôs a investigar. Determinar para qual intervalo uma pequena variação na quantidade de dias, para resolver uma disputa comercial na justiça, produz uma melhora significativa na qualidade de vida, e qual a variação necessária no número de dias para que o Brasil 
Almeida, L. M. W.; Silva, K. A. P.

tenha IDH alto são respostas que não ficam diretamente visíveis no modelo. A busca das alunas por estas respostas sinaliza a ação cognitiva Interpretação e Validação.

No que se refere a uma análise mais completa para buscarem como variações no número de dias provocam variações no IDH, as alunas determinaram a derivada do modelo encontrado e construíram seu gráfico conforme mostra a Figura 5.

Figura 4. Representação gráfica de $Q(j)$

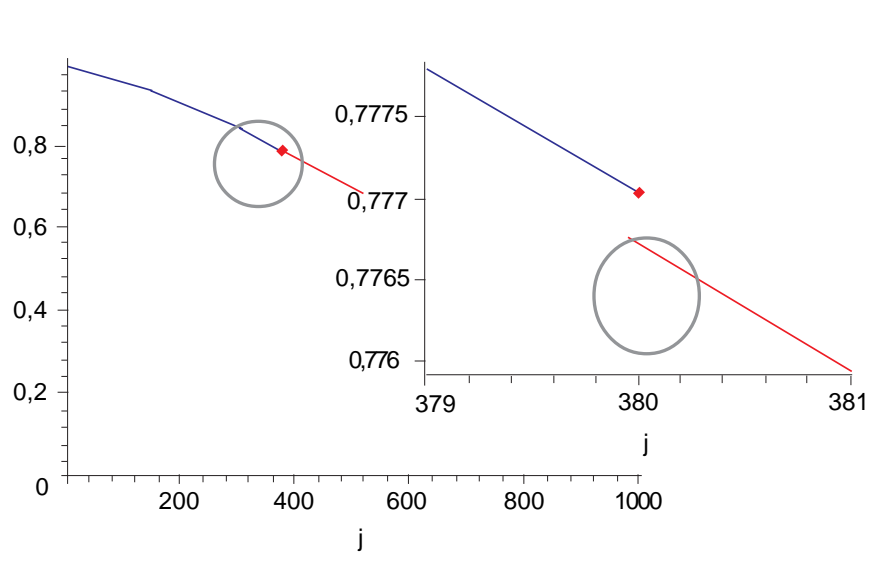

Fonte: Silva (2008, p. 131)
Figura 5. A derivada $Q^{\prime}(j)$

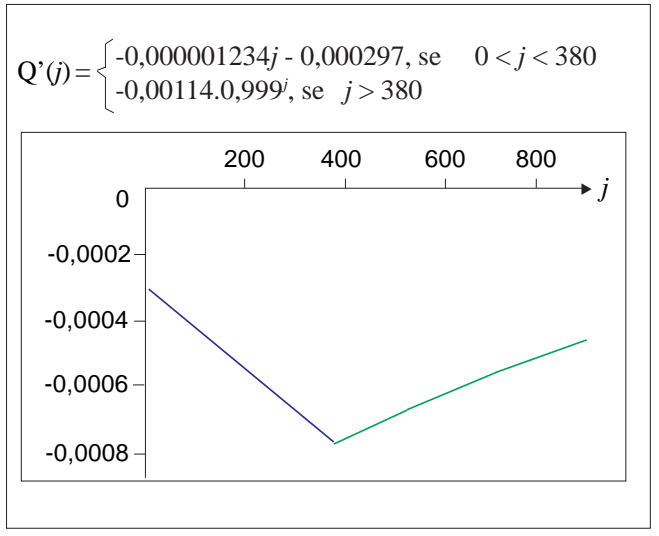

Fonte: Elaborada pelos autores

É justamente este gráfico que faz as alunas apresentarem a conclusão:

"Observando a função derivada, notamos que próximo de $j=380$, uma pequena variação na quantidade de dias para resolver uma disputa comercial na justiça implica numa melhora significativa na qualidade de vida". (transcrição do relatório das alunas)

Para abarcar, do ponto de vista matemático, a questão referente à redução necessária no número de dias para o Brasil, as alunas fizeram as substituições adequadas no modelo obtido (Figura 5). Neste caso as alunas afirmam que:

"Segundo o modelo construído e, realizando os cálculos pertinentes, verificamos que para apresentar IDH $=0,8$ é preciso que o Brasil reduza de 380 para 349 dias a quantidade de dias necessária para resolver uma disputa comercial na justiça. Assim, se só dependesse de justiça 
rápida e eficiente, uma melhora de 31 dias significaria a classificação do Brasil como um país com ótima qualidade de vida e um alto IDH”. (transcrição do relatório das alunas)

A apresentação destas conclusões sinaliza uma inferência Explicação no que se refere ao interesse e a necessidade das alunas em realizar uma análise detalhada da situação. No que se refere à vontade de apresentar uma 'resposta irrefutável', conjecturamos que se trata de inferência dedutiva do tipo Procedimento Avaliativo. A apresentação destas respostas sinaliza que as alunas fizeram a análise da representação matemática associada ao problema, tanto em relação aos procedimentos matemáticos quanto em relação à adequação do modelo para a situação. Neste sentido, a ação cognitiva que parece se evidenciar é Interpretação e Validação.

Em temos gerais, a análise que realizamos revela que, no decorrer do desenvolvimento da atividade, há fortes indícios de que as alunas realizaram ações cognitivas importantes. Além disso, inferências dos alunos também puderam ser evidenciadas em diversos momentos. A Figura 6 apresenta um resumo destas ações e inferências dos alunos nesta atividade.

Figura 6. Modos de inferência e ações cognitivas da atividade de modelagem

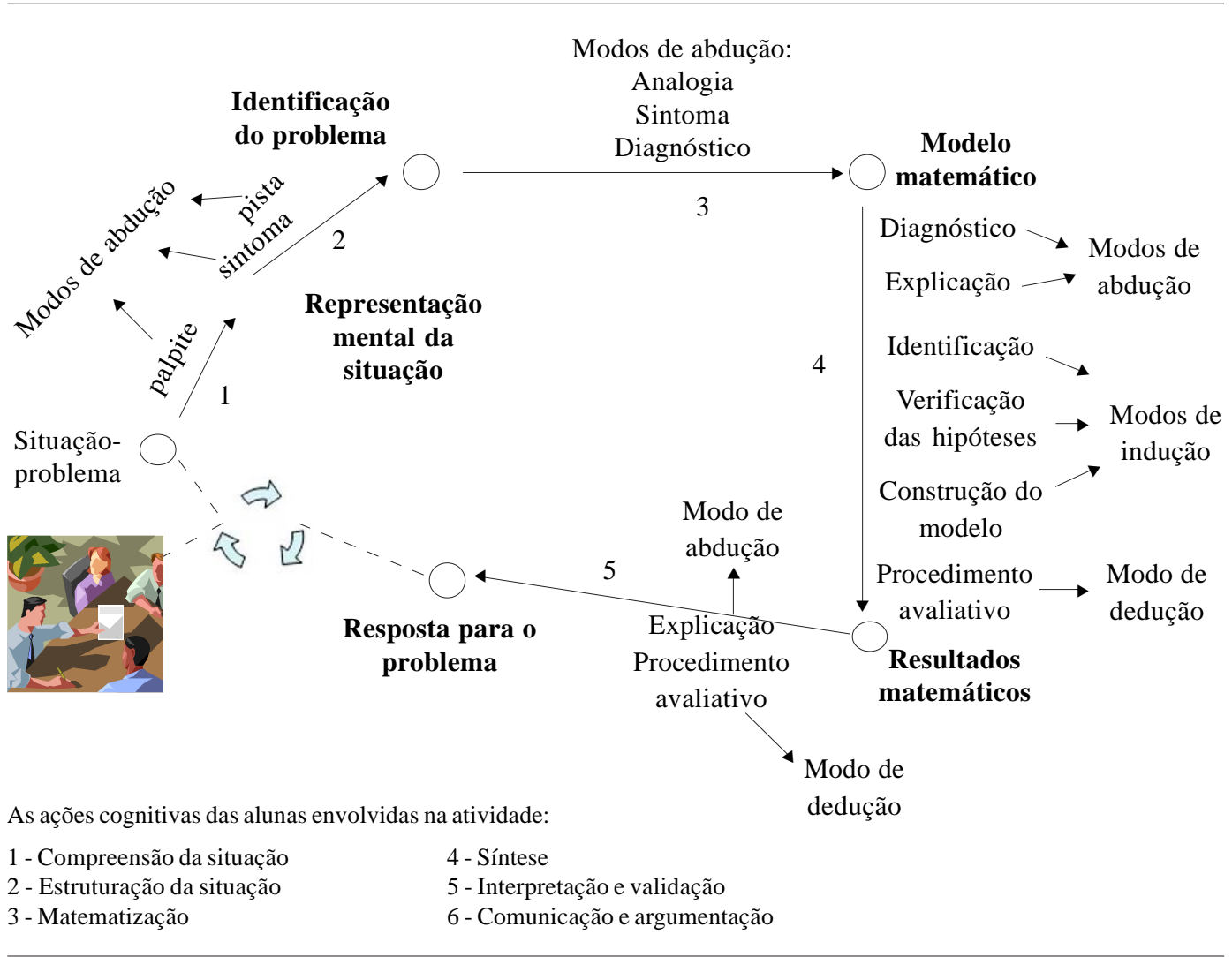

Fonte: Elaborada pelos autores 
Almeida, L. M. W.; Silva, K. A. P.

\section{Considerações finais}

Refletir a construção de conhecimento sob a ótica da semiótica peirceana requer entender a construção de signos matemáticos e investigar processos mentais associados a essa construção. Esta perspectiva parece estar em sintonia, também, com a argumentação de Santaella (2007), já enunciada neste texto, de que os modos de inferência peirceana constituem uma função essencial da mente cognitiva e que a 'vida' do pensamento é uma questão de formação e/ou exercício de certos hábitos de inferência.

Nesse sentido, esse texto sinaliza que a ação educativa, especialmente no âmbito da sala de aula, pode fazer a diferença na constituição de conhecimento pelo aluno. Os resultados da análise realizada nos encorajam a argumentar que, quando os alunos fazem o estudo de um conceito matemático a partir de situações-problema da realidade com dados reais e desenvolvem a representação matemática da situação, eles realizam uma atividade investigativa que requer diferentes tipos de raciocínio e proporciona diferentes ações cognitivas.

Desse modo, defendemos que a modelagem matemática constitui uma alternativa pedagógica que pode proporcionar ações cognitivas importantes e requer diferentes modos de inferência, ou seja, é possível estabelecer uma associação entre os modos de inferência estabelecidos por Kehle e Cunningham (2000) e as ações cognitivas dos alunos que caracterizamos neste texto e apresentamos na Figura 1.

A análise da atividade de modelagem matemática evidencia que diferentes modos de inferência podem ser associados às diferentes ações cognitivas, corroborando com o que Kehle e Cunningham (2000) afirmam de que os modos de inferência não correspondem a categorias distintas nas quais todas as formas de ocorrências de semiosis podem ser classificadas como um ou outro modo, mas como uma forma de identificar os modos de inferência (abdução, dedução e indução) no desenvolvimento de uma atividade de modelagem matemática.

Considerando as especificidades de cada situação-problema e de cada intérprete, uma quantidade maior de modos de inferências pode ser evidenciada; no entanto, isso pode não significar que o modelo obtido é melhor ou pior para representar a situação. Todavia, conforme a atividade analisada, a relação entre modos de inferência e ações cognitivas sinaliza a construção de conhecimento dos alunos, e, aí sim, podemos conjecturar que mais ou menos indícios dessa construção podem ser evidenciados. 
Semiótica e as ações cognitivas dos alunos ...

\section{Referências}

ALMEIDA, L. M. W.; FERRUZZI, E. C. Uma aproximação socioepistemológica para a modelagem matemática. Alexandria, Florianópolis, v. 2, n. 2, p. 117-134, 2009.

ALMEIDA, L. M. W.; BRITO, D. Atividades de modelagem matemática: que sentido os alunos podem lhe atribuir? Ciência \& Educação, Bauru, v. 11, n. 3, p. 483-498, 2005.

CORREIA, C. M. C. Fundamentos da semiótica peircena. In: FÓRUM DE ESTUDOS LINGUÍSTICOS, 9., 2007, Rio de Janeiro. Atas... Rio de Janeiro: UERJ, 2007.

ECO, U. Semiótica e filosofia da linguagem. São Paulo: Ática, 1991.

FERRI, R. B. Theoretical and empirical differentiations of phases in the modeling process. ZDM, Heidelberg, v. 38, n. 2, p. 86-95, 2006.

FIDALGO, A. Semiótica: a lógica da comunicação. Covilhã: Universidade da Beira Interior, 1998.

GOMES, A. D. T.; BORGES, A. T.; JUSTI, R. Processos e conhecimentos envolvidos na realização de atividades práticas: revisão da literatura e implicações para a pesquisa.

Investigações em Ensino de Ciências, Porto Alegre, v. 13, n. 2, p.187-207, 2008.

KEHLE, P. E.; CUNNINGHAM, D. J. Semiotics and mathematical modeling.

International Journal of Applied Semiotics, Madison, v. 3, n. 1, p. 113-129, 2000.

KEHLE, P.; LESTER JR., F. K. A semiotic look at modeling behavior. In: LESH, D.;

DOERR, H. Beyond constructivism: models and modeling perspectives on mathematics problem solving, learning, and teaching. Hillsdale: Erlbaum, 2003. p. 97-122.

KESKE, H. A. Incidentes peirceanos: a lógica do constante jogo das abduções. In: SEMINÁRIO INTERNACIONAL DE COMUNICAÇÃO, 9., 2007, Porto Alegre. Anais... Porto Alegre, PUCRS, 2007.

KLAHR, D.; DUNBAR, K. Dual space search during scientific reasoning. Cognitive Science, Hoboken, v. 12, n. 1, p. 1-48, 1988.

KLAYMAN, J.; HA, Y. Confirmation, disconfirmation, and information in hypothesis testing. Psychological Review, Washington, v. 94, n. 2, p. 211-228, 1987.

LESH, R.; CARMONA, G.; HJALMARSON, M. Models and modeling working group. In: ANNUAL CONFERENCE OF THE NORTH AMERICAN CHAPTER OF THE INTERNATIONAL GROUP FOR THE PSYCHOLOGY OF MATHEMATICS EDUCATION, 28., 2006, Mérida. Proceedings... Mérida: PMENA, 2006. p. 1-4.

PEIRCE, C. S. Escritos coligidos. São Paulo: Abril Cultural, 1980. (Os pensadores). Semiótica. 3. ed. São Paulo: Perspectiva, 2005. (Estudos, 46).

SANTAELLA, L. O que é semiótica. São Paulo: Brasiliense, 2008. (Coleção primeiros passos, 103).

Semiótica aplicada. São Paulo: Thomson Learning, 2007. 
Almeida, L. M. W.; Silva, K. A. P.

SILVA, C.; RYDLEWSKI, C. Brasil: no coração do mercado. Veja, São Paulo, n. 1860, p. 36-39, 30 jun. 2004.

SILVA, K. A. P. Modelagem matemática e semiótica: algumas relações. 2008. 212 f. Dissertação (Mestrado em Ensino de Ciências e Educação Matemática) - Universidade Estadual de Londrina, Londrina, 2008.

VERTUAN, R. E. Um olhar sobre a modelagem matemática à luz da teoria dos registros de representação semiótica. 2007. 141 f. Dissertação (Mestrado em Ensino de Ciências e Educação Matemática) - Universidade Estadual de Londrina, Londrina, 2007.

Artigo recebido em 23/06/2011. Aceito em 02/02/2012. 